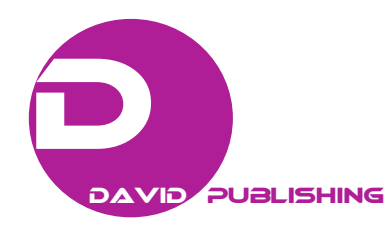

\title{
Urban Growth Management through Travel Demand Modeling in Washington and Oregon
}

\author{
Jinxiang Ren \\ Oregon Department of Transportation, 555, 13th St. NE, \#2, Salem, Oregon 97301, USA
}

\begin{abstract}
Among the fast growing states in the USA, the States of Washington and Oregon have enacted legislative land use and transportation concurrency/balancing planning policies for orderly urban growth management since 1990 and 1991, respectively. Regional or urban travel demand forecasting models play an instrumental role in implementing the Washington GMA (Growth Management Act) and the Oregon TPR (Transportation Planning Rule). Both program- and project-level modeling approaches to urban land use/transportation system management are evaluated through the selected cities in Washington and Oregon.
\end{abstract}

Key words: Urban growth management, travel demand modeling, transportation planning, land use-transportation concurrency.

\section{Introduction}

At the beginnings of 1990s, both state governments of Washington and Oregon anticipated significant urban growths in the coming decades, and therefore enacted respective legislations to mandate that the state, regional and local jurisdictions establish their land use/transportation concurrency or balancing processes to effectively manage urban growth for their community livability, economic vitality and environmental sustainability.

The Washington GMA (Growth Management Act) [1] states: "uncoordinated or unplanned growth lacks of common goals, threatens the environment, impedes sustainable economic development, and harms the public health, safety, and high quality of life." Apparently, urban growths need to be planned and managed in a coordinated way. Since land use assumptions are used in estimating travel demand, how will they be reassessed to ensure that transportation LOS (level of service) standards will be met? A travel demand forecasting model (hereafter referred to as the Model) plays an instrumental role in assessing the current and future land use/transportation

Corresponding author: Jinxiang Ren, P.E., MS and MUP, Sr. Transportation Analyst/Modeler; research field: travel demand forecasting. concurrencies.

In Oregon, TPR (transportation planning rules) Section 0060 [2] was enacted by the State of Oregon Legislature in 1991. On the same token as GMA, TPR requires "local governments to ensure that allowed land uses are consistent with the identified function, capacity, and performance standards of the facility measured at the end of the planning period." Four acceptable approaches are considered best practices by TPR, such as: "legislating consistence, mitigating problems directly or improving alternative modes or facility, and 'partial mitigation' allowed."

\section{Travel Demand Modeling for GMA/TPR}

Both GMA and TPR identify the need to measure and manage the current and future travel demand growths for urban areas; therefore, the Model reasonably becomes an essential "tool of the trade" as it closely links the land use assumptions to be implemented on transportation systems.

GMA allows regional and local jurisdictions some flexibility to establish their own respective transportation system LOS standards according to their specific needs or traffic congestion allowances while TPR requires that the local jurisdictions follow the OHP (Oregon highway planning) mobility standards. 
No matter what urban growth management mechanisms or approaches are implemented in Washington and Oregon, without utilizing the Model regional and local jurisdictions would not be able to adequately measure the transportation system performance changes or significant traffic impacts made by an individual land use proposal or cumulative effects of multiple land use proposals.

Three representative cities, such as: Bellevue and Olympia in Washington, and Grants Pass in Oregon, are studied to demonstrate how the program level urban growth management is implemented and monitored to account for cumulative effects of land use development proposals, and how an individual development project is modeled for its traffic impacts on the transportation concurrency.

\section{Bellevue Concurrency Program}

In the last 30 years, the population and employment in the City of Bellevue have almost doubled, growing from 75,000 residents and 78,000 employees in mid-80s' to currently 140,000 residents and 148,000 employees, respectively. In anticipation of downtown Bellevue growth, the first Bellevue Model was built for its 20-year downtown implementation plan in late 1980s. In the early 1990s, the Bellevue Model was expanded to forecast the land use and network details in the eastside cities of Kirkland and Redmond in response to the state GMA legislation. The Model is therefore called BKR Model.

BKR Model serves one of the primary purposes_annual concurrency update. The Concurrency Model is built by adding annually approved land development permits or design review projects and the city council adopted six-year CIP (capital improvement program) to the base year BKR Model. At the program level, the cumulative effects of all the annually approved developments will be forecast on the six-year Model platform and compared with and without CIP scenarios. For every proposed development project, which is initially estimated by using the ITE (Institute of Transportation Engineers) Trip Generation Manual to generate 20 or more PM peak hour vehicular trips, a development review modeling process is followed as well. Fig. 1 displays the concurrency model build and application process at both program and project levels [3].

As described in the introduction of the "2007 City of Bellevue annual Concurrency Update," [3] "The City of Bellevue's adopted Traffic Standards Code (TSC Chapter 14.10) [4] establishes the city's transportation concurrency requirements, LOS standards and methodologies, and compliance determination process." The TSC defines "concurrency" whereas "the city must

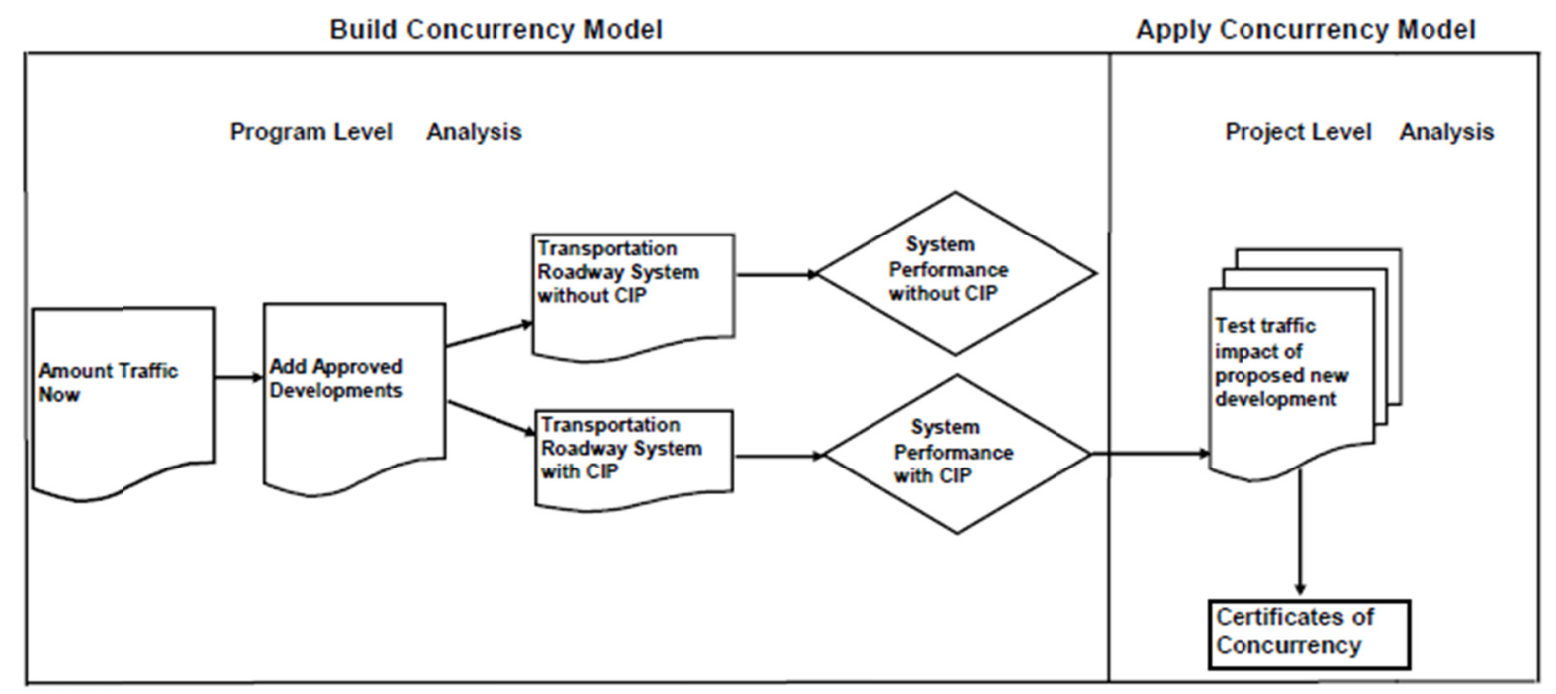

Fig. 1 City of Bellevue concurrency model build and application. 
enforce an ordinance precluding approval of a proposed development if that development would cause the level of service of a transportation facility to fall below the city's adopted standard, unless a financial commitment is in place to complete mitigating transportation improvements or strategies within 6 years."

Under the "Traffic Standard Code," the Bellevue urban area is divided into 14 MMAs (mobility management area), which are classified according to its MMA land use characteristics and boundaries, such as: downtown, commercial, industrial, residential or mixed-use MMAs. Through this concurrency methodology, the city can use existing traffic counts and model volumes to post-process an average PM peak hour of 2-hour intersection volumes, calculate the system intersection LOS, and figure out how much reserve capacities are available within its MMAs.

Within each MMA designation, it is clearly shown in Table 1 [3]: Comparison of concurrency system intersection LOS snapshots, what percentages of reserve capacities would be available, how many system intersections exceed the TSC standards, and if the number of intersections over the $\mathrm{V} / \mathrm{C}$ standard exceeds its MMA allowances. In addition, the comparisons between with and without CIP demonstrate how much the CIP would improve the average MMA $\mathrm{V} / \mathrm{C}$ ratios and reduce the number of system intersections over the V/C standard. What's so important, the TSC designs such modeling mechanism and analytical approaches to proactively identify where the next potential improvement projects should be programmed for the city-wide land use and transportation concurrency.

\section{Olympia Concurrency Program}

As the State Capital of Washington, the small-sized Olympia has a population size of over 50,000 in 2000. The city's transportation concurrency program shares some similarities to the medium-sized City of Bellevue, but takes a simpler approach at both the program level and the project level.

"The City of Olympia 2009 Annual Concurrency Report" [5] states "in 1995 the city established four concurrency analysis zones to meet two internal consistency requirements:

To maintain concurrency between a jurisdiction's infrastructure investment and growth, development is not allowed until and unless transportation improvements or strategies are in place at the time of development or within 6 years of when the project is on line.

Table 1 Comparison of concurrency system intersection LOS snapshots.

\begin{tabular}{|c|c|c|c|c|c|c|c|c|c|c|}
\hline \multicolumn{4}{|c|}{2013 MP6-R9 Concurrency Model Platform } & \multicolumn{3}{|c|}{2013 W/O CIP } & \multicolumn{3}{|c|}{2013 W/ CIP } & \multirow[b]{2}{*}{$\begin{array}{c}\text { Change in V/C } \\
\text { Rattlo" From } \\
\text { mp6r8 to } \\
\text { mp6r9 }\end{array}$} \\
\hline MMA\# & MMA Name & $\begin{array}{c}\text { LOS } \\
\text { Standard } \\
\text { (Volume/ } \\
\text { Capacity } \\
\text { Ratios) }\end{array}$ & $\begin{array}{l}\text { No of } \\
\text { Intersections } \\
\text { Allowed Over } \\
\text { the Standard }\end{array}$ & $\begin{array}{c}\text { Average V/C } \\
\text { Ratio }\end{array}$ & $\begin{array}{c}\text { \% Capacity } \\
\text { Available }\end{array}$ & $\begin{array}{c}\text { No of } \\
\text { Intersections } \\
\text { Over the } \\
\text { Standard }\end{array}$ & $\begin{array}{c}\text { Average V/C } \\
\text { Ratio }\end{array}$ & $\begin{array}{c}\% \text { Capacity } \\
\text { Available }\end{array}$ & $\begin{array}{c}\text { No of } \\
\text { Intersections } \\
\text { Over the } \\
\text { Standard }\end{array}$ & \\
\hline 1 & North Bellevue & 0.85 & 3 & 0.660 & $22 \%$ & 0 & 0.651 & $23 \%$ & 0 & -0.009 \\
\hline 2 & Bridle Trails & 0.80 & 2 & 0.537 & $33 \%$ & 0 & 0.522 & $35 \%$ & 0 & -0.015 \\
\hline 3 & Downtown & 0.85 & 9 & 0.762 & $20 \%$ & 1 & 0.730 & $23 \%$ & 1 & -0.032 \\
\hline 4 & Bel-Red/Northup & 0.90 & 10 & 0.720 & $20 \%$ & 0 & 0.685 & $24 \%$ & 0 & -0.035 \\
\hline 5 & Crossroads & 0.90 & 2 & 0.677 & $25 \%$ & 0 & 0.685 & $24 \%$ & 0 & 0.008 \\
\hline 6 & North-East Bellevue & 0.80 & 2 & 0.649 & $19 \%$ & 0 & 0.639 & $20 \%$ & 0 & -0.010 \\
\hline 7 & South Bellevue & 0.85 & 4 & 0.643 & $24 \%$ & 0 & 0.629 & $26 \%$ & 0 & -0.014 \\
\hline 8 & Richards Valley & 0.85 & 5 & 0.637 & $25 \%$ & 1 & 0.632 & $26 \%$ & 1 & -0.005 \\
\hline 9 & East Bellevue & 0.85 & 5 & 0.771 & $9 \%$ & 3 & 0.763 & $10 \%$ & 2 & -0.008 \\
\hline 10 & Eastgate & 0.90 & 4 & 0.665 & $28 \%$ & 1 & 0.616 & $32 \%$ & 0 & -0.049 \\
\hline 11 & Newcastle & 0.80 & 3 & 0.769 & $4 \%$ & 0 & 0.771 & $4 \%$ & 0 & 0.002 \\
\hline 12 & Overlake & 0.95 & 9 & 0.677 & $29 \%$ & 0 & 0.661 & $30 \%$ & 0 & -0.016 \\
\hline \multirow[t]{2}{*}{13} & Factoria & 0.85 & 5 & 0.817 & $14 \%$ & 1 & 0.815 & $14 \%$ & 1 & -0.002 \\
\hline & TOTAL & & 63 & & & 7 & & & 5 & -0.185 \\
\hline
\end{tabular}


Annual review of concurrency management system for cumulative effects along with annual update of Capital Facility Plan (CFP) and Comprehensive Plan.”

The Olympia concurrency management system utilizes the regionally developed Model to estimate the vehicle trip growths within six years and to evaluate the system deficiencies due to annual traffic growths and 6-year traffic growths. Within the Olympia four concurrency zones, the 6-year future trip generation is estimated at TAZ (traffic analysis zones) by the regional concurrency Model.

The regional base year Model is updated and calibrated for the existing condition. The concurrency Model is built upon the base year model by applying the regional 6-year land use forecasts and 6-year TFP (transportation facility plan) projects on the model network. Six-year traffic change forecasts will be post-processed to the base year traffic counts for identified intersection LOS analysis.

Two levels of service standards are established: downtown concurrency zone allows more congestion than the other three concurrency zones. Similar to Bellevue, average one hour of PM peak two-hour LOS allows traffic peak spreading over a two-hour period of time than a single PM peak hour.

Through this travel demand modeling and average one hour of PM 2-hour traffic analysis mechanism, the city's concurrency program examines potential traffic problems and provides further verification of transportation system improvement needs.

At a project level, a per trip cost is estimated for each concurrency zone so that a development will simply be charged with how many PM peak hour trips are generated and where they are originated and destined in terms of TAZs and concurrency zones. It's simpler and easier for developers to understand that the central Olympia concurrency zone is charged higher impact fees than other three zones.

\section{Oregon Grants Pass TPR Implementation}

At a program level in Oregon, each city or county jurisdiction is required by the TPR to update its TSP (transportation system plan), which will look into the current travel demand through the base year model and forecast the future 20-year travel demand within the UGB (urban growth boundary). The financially committed transportation improvement projects are coded into the future demand model. The system effects are determined and evaluated at the end of planning period. The local TSP should be consistent with the same land use assumptions as its corresponding adopted RTP (regional transportation plan).

The Oregon RTP and TSP are equivalent to the program level land use and transportation concurrency measures in Washington. Although the urban growth areas are not divided further for their mobility management areas unlike in Bellevue or Olympia, the UGB plays an important role in containing the development within the UGB, which will be renewed every 10 years with the urban growth occurring. Some cities maintain urban reserve areas for potential city annexation to be either within UGB or city limit.

In the Mid-Rogue Valley MPO, the Grants City Model was used to evaluate the base year 2010 and future year 2040 transportation system performance at regional corridor level. As shown in Fig. 2: the 2040 Future Year Grants Pass Central City Congestion Measurements [6], the streets in red indicate that the volume/capacity ratios equal or exceed 0.90 and the streets in blue for $\mathrm{V} / \mathrm{C}$ ratios between $0.80-0.89$.

Table 2 displays the roadway lane miles by $\mathrm{v} / \mathrm{c}$ ratios to indicate how many or percentages of lane miles are congested between base conditions and future conditions with/without RTP projects [6]. This is program-level system evaluation based on the Model.

For an individual development proposal, usually the 20-year long-term RTP or TSP model will be used to add the individual development trip generation (by ITE Trip Generation Manual), and then a model run with the development will be initiated to determine the traffic growths. Then, the Model volumes 

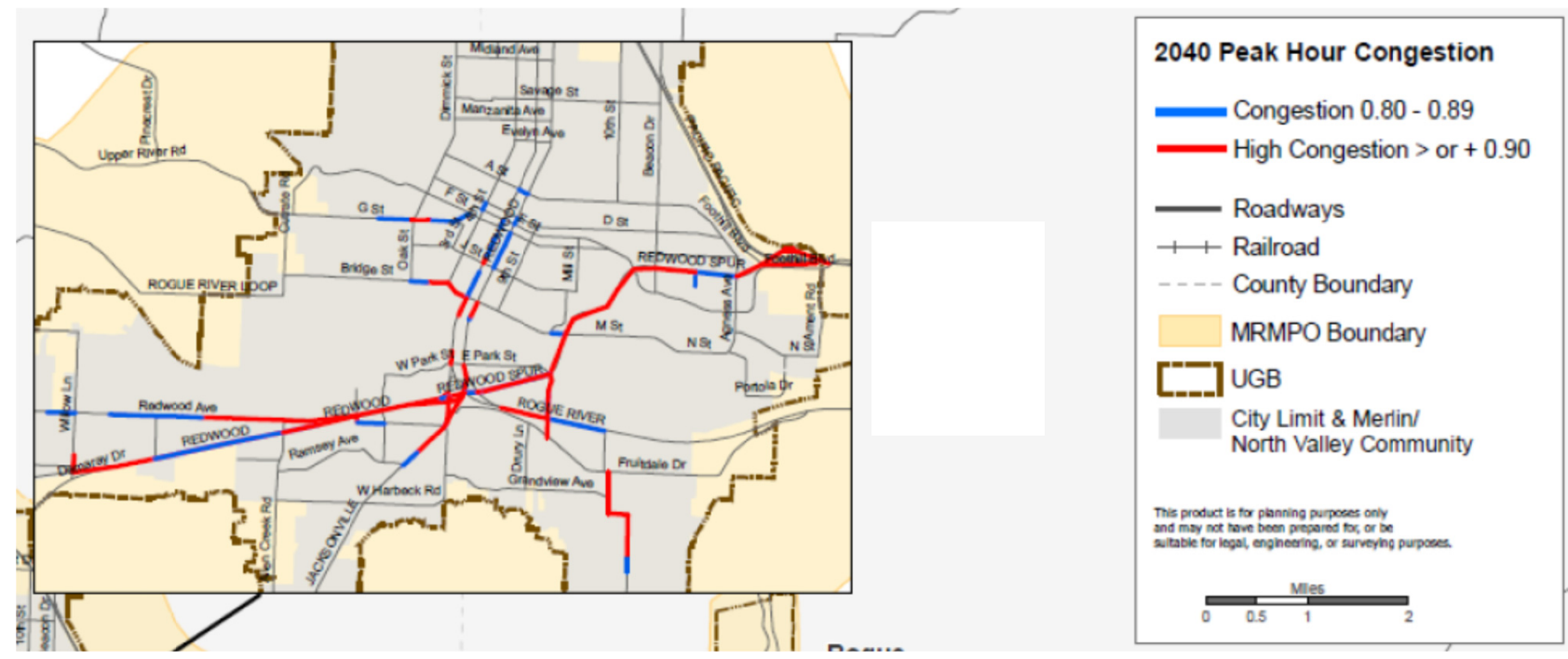

Fig. 2 The 2040 future year grants pass central city congestion measurement.

Table 2 Grants pass RTP PM peak hour \% of lane miles by V/C ratio ranges.

\begin{tabular}{|c|c|c|c|c|c|c|}
\hline \multirow{2}{*}{$\begin{array}{c}\text { Demand/Capacity } \\
\text { Ratio Range }\end{array}$} & \multicolumn{2}{|c|}{$\begin{array}{c}\text { Reference } \\
\mathbf{2 0 1 0}\end{array}$} & \multicolumn{2}{c|}{$\begin{array}{c}\text { No-RTP } \\
\mathbf{2 0 4 0}\end{array}$} & \multicolumn{2}{c|}{$\begin{array}{c}\text { RTP Build } \\
\mathbf{2 0 4 0}\end{array}$} \\
\cline { 2 - 7 } & $\begin{array}{c}\text { Lane } \\
\text { Miles }\end{array}$ & $\begin{array}{c}\text { \% of Total } \\
\text { Lane Miles }\end{array}$ & $\begin{array}{c}\text { Lane } \\
\text { Miles }\end{array}$ & $\begin{array}{c}\text { \% of Total } \\
\text { Lane Miles }\end{array}$ & Lane Miles & $\begin{array}{c}\% \text { of Total } \\
\text { Lane Miles }\end{array}$ \\
\hline $\mathbf{0 . 0}-\mathbf{0 . 5 9}$ & 608 & $94 \%$ & 585 & $91 \%$ & 592 & $91 \%$ \\
\hline $\mathbf{0 . 6 0}-\mathbf{0 . 6 9}$ & 12 & $2 \%$ & 14 & $2 \%$ & 13 & $2 \%$ \\
\hline $\mathbf{0 . 7 0 - 0 . 7 9}$ & 12 & $2 \%$ & 10 & $2 \%$ & 12 & $2 \%$ \\
\hline $\mathbf{0 . 8 0}-\mathbf{0 . 8 9}$ & 6 & $1 \%$ & 9 & $1 \%$ & 9 & $1 \%$ \\
\hline $\mathbf{0 . 9 0}-\mathbf{0 . 9 9}$ & 2 & $0 \%$ & 9 & $1 \%$ & 7 & $1 \%$ \\
\hline$>\mathbf{1 . 0}$ & 3 & $1 \%$ & 15 & $2 \%$ & 15 & $2 \%$ \\
\hline Total & $\mathbf{6 4 3}$ & & $\mathbf{6 4 3}$ & & $\mathbf{6 4 8}$ & \\
\hline
\end{tabular}

* Congestion defined as model links with demand/capacity ration $\geq 0.90$.

are post-processed to calculate PM peak hour intersection $\mathrm{V} / \mathrm{C}$ ratios and level of service. Therefore, individual project-level traffic impacts are identified and mitigation measures are sought to monitor the system balance at the end of the project completion.

\section{Evaluation of Modeling Approaches}

Although the common goal of GMA and TPR is for orderly urban growths and balanced economic development with transportation system improvements to accommodate the urban growths, their respective modeling approaches share some similarities and differences.

Both GMA and TPR measure the concurrency conditions by cumulative effects of all approved developments and individual effects of a development proposal. GMA looks at short-term 6-year land use and transportation concurrency system performance while TPR uses longer-term 20-year future scenario model for its program-level RTP and TSP. Conventionally, faster growing urban communities as in Washington need to consider short-term modeling for concurrency while small or medium-sized cities in Oregon appropriately consider longer terms of modeling for concurrency/balance.

The cities of Bellevue and Olympia use the Model post-processed average peak hour of PM peak 2 hour traffic volumes for their LOS snapshot to allow traffic 
peak spreading effects for two-hour time period. The Oregon cities only use the PM peak single-hour approach to its LOS or volume/capacity ratio calculation since its future model platform is 20-year longer horizon, by which peak spreading may happen.

The City of Bellevue considers the actually approved development permits and the adopted/committed 6-year CIP while the City of Olympia uses the regional TRPC forecast 6-year model platform based on the regional land use forecast assumptions. As a much faster-growing community, Bellevue TSC monitors its land use/transportation concurrency more strictly than Olympia's concurrency program; however, Bellevue commits much more modeling resources than Olympia.

In Oregon small urban areas and MPOs, the future year scenario land use assumptions follow the state population and employment forecasts but are reviewed in detail by the local planners. ODOT transportation planning analysis unit has long maintained Models for Oregon small urban areas and 5 MPOs to help with the TPR implementation. Consolidated modeling resources and approaches save public funding and are more effective in both program- and project-level modeling implementations.

\section{Conclusion}

For almost three decades, travel demand modeling has been in effective use for urban land use/transportation concurrency program and development review modeling in local and regional jurisdictions of both Oregon and Washington because of their respective state legislations on urban growth management.
In retrospect, the above-discussed modeling approaches demonstrate that both program- and project-level transportation system performance management is made possible by using a regional or urban travel demand forecasting model. The model integrates land use and transportation system by quantitatively assessing individual and cumulative traffic impacts of developments, and measuring land use/transportation system balancing or concurrency.

Without the Model, short- or long-term future traffic forecasting is more like a "guessing game"; the GMA and TPR could hardly be effectively implemented; therefore, local and regional jurisdictions could hardly have enjoyed the direct benefits of proactively (rather than reactively as in the past) prioritizing their transportation system improvements or financing strategies to meet their system needs.

\section{References}

[1] State of Washington Laws. 1990. 1st ex. "Session." Chapter 17 [Substitute House Bill No. 2929] Growth Management.

[2] Oregon State Department of Transportation. 2013. Development Review Guidelines 2013 Chapter 3.2: Transportation Planning Rule (TPR) Review.

[3] Ren, J., and Liljeblad, K. 2002-2007. "City of Bellevue, Department of Transportation, Transportation Modeling and Analysis Group." Final Report: Concurrency Update: LOS Snapshot as of September 15, 2007.

[4] City of Bellevue, Department of Transportation. 1993-2009. Chapter 14 10: Traffic Standards Code.

[5] Smith, D. and Ren, J. 1998-2002. City of Olympia, Public Works Department, City of Olympia 2009 Annual Concurrency Report.

[6] Mid-Rogue Metropolitan Planning Organization. 2016. Chapter 11: System Performance, Regional Transportation Plan (RTP) 2015-2040. 